\title{
Determinant Factors of Women's Participation in Functional Adult Literacy Programme in Bahir Dar Zuria Woreda, North West Ethiopia
}

\author{
Kassahun Tiruaynet \\ Debre Berhan University, Debre Berhan, Ethiopia \\ Email: tirukassu21@gmail.com
}

Received 25 May 2015; accepted 9 June 2015; published 18 June 2015

Copyright (C) 2015 by author and OALib.

This work is licensed under the Creative Commons Attribution International License (CC BY). http://creativecommons.org/licenses/by/4.0/

(c) $\underset{\mathrm{EY}}{ } \mathrm{i}$ Open Access

\section{Abstract}

Functional Adult Literacy Programme has a central role to play in boosting the social, economical and political development of the country in general and the beneficiaries in particular. It is apparent that the government of Ethiopia makes tremendous efforts to reduce the rate of illiteracy and enhance new skills to improve standard of living for adult learners through Functional Adult Literacy programme in the country. Nevertheless, studies and reports show that literacy rate and participation of women in Functional Adult Literacy Programme across location are insignificant in magnitude. Therefore, the aim of the present study was designed to identify factors affecting women's participation in functional adult literacy related to socio-demographic and organizational factors at Bahir Dar Zuria Woreda, North West Ethiopia. Quantitative research approach with descriptive survey research design was employed. About 184 registered women were selected from 3 rural kebeles of Literacy Centers through simple random sampling with lottery techniques by taking their names from the total number of registered women. Descriptive statistics, univariate and multiple binary logistic regression analyses were used to determine the effect of factors on the outcome variable and to control possible confounders. Statistical tests were done at 0.05 level of significance. The study revealed that $65(35.3 \%)$ and $119(64.7 \%)$ of respondents were participant and non-participant women in Functional Adult Literacy Centers respectively. Results on multiple logistic regression provided that married women (AOR $=0.135$ [95\% CI: $0.024-0.758$ ] $)$ and divorced women (AOR $=0.054$ [95\% CI: 0.006 - 0.529]) both relative to widowed women; high work load (AOR = 3.326 [95\% CI: 1.261 - 8.768]) relative to low work load; and class schedule conflict (AOR $=8.009$ [95\% CI: $3.190-20.11]$ ) relative to no class schedule conflict have significant association. Local government body in collaboration with Adult Education Bureau is recommended to provide massive awareness creation about gender equality for adult learners and the local communities. 


\title{
Keywords
}

\section{Functional Adult Literacy, Women, Participation, Bahir Dar Zuria Woreda}

\author{
Subject Areas: Gender and Development Studies
}

\section{Introduction}

Functional Adult Literacy programme is the comprised programme which is providing skills of reading, writing and numerical calculating, and basic vocational skills that are linked to occupational desires of the productive citizens [1] [2]. According to UNSCO report, adult Literacy programme encompassed family literacy and intergenerational learning; health promotion and HIV prevention; empowerment and economic self-sufficiency; languages in basic education; and Information and Communication Technologies [3]. Functional Adult Literacy is therefore very important and the most effective strategies for ensuring that the skills of functional literacy and numeracy do support the struggle of very poor to develop livelihoods sufficient to lift themselves out of poverty. It also supports to create a healthy social status of the beneficiaries [1] [4] [5].

In spite of this, women often lack the opportunity to reduce their illiteracy problems and develop new skills to improve their standard of living through Functional Adult Literacy Programme in developing countries. This is strongly supported by a study showed that ninety-five percent of the world's illiterate people live in developing countries and about 70 percent are women [6]. The very recent report also indicates that about 774 million adults are part of the global illiterate population who lack basic literacy skills and two-thirds of the global illiterate populations were women who are found most of them in developing countries [7].

Studies related to women's participation in Functional Adult Literacy Programme and its challenges faced in Adult Literacy Centers are inadequate in developing countries; however, few studies identified impediments of women's participation in Literacy Centers. For instance, a study in Kenya revealed that most adult women could not attend properly the programme. The finding of the study showed that marital status, work load and family perception especially her husband were factors affecting participation of women in Adult Literacy programme [8]. Likewise, a study in Kabompo District in North Western province in Zambia revealed that socio-cultural constraints (marital status, work load and perception of family) and perception regarding the value of education in general regretted participation of women in adult literacy programme [9].

In the Federal Democratic Republic of Ethiopia, the Ministry of Education has been developed the National Adult Education Strategy which uses to reduce the rate of illiteracy in both males and females. It also uses to enhance skill full human power at national level thereby contributing to Ethiopia's Program for Accelerated Sustainable Development to End Poverty (PASDEP) [10] [11]. But adult education programmes weren't relevant to the day-to-day life of the adults at the beginning time [11]. In order to alleviate the adult education problems integrate learning materials of skill based, work oriented and community based adult education programme complied by ministry of education in collaboration with different development ministries of the country [11]. These integrated materials made in Education Sector Development Programme III and its action plan incorporate basic literacy and numeracy skills, primary health care, prevention of diseases [such as Malaria, HIV/AIDS, etc], family planning, environment, agriculture, marketing, etc. [11] [12].

Functional Adult Literacy programme in Ethiopia has to do a lot. However, studies and reports show that the literacy rate and participation of women in Functional Adult literacy programme at national level are low. In light of this, a study conducted by Mammo [13] indicated that, "illiterates in Ethiopia share those attributes that are common among people with high level of illiteracy: they are mostly poor and marginalized, the women being the most deprived of all the groups." The statistical figures of the Central Statistical Authority of Ethiopia from the document of Demographic and Health Survey (DHS) also clearly showed literacy disparity between women and men. Even though it is low for both sexes from the country, the proportion of women illiterate who cannot read a whole sentence is approximately $77 \%$ [14]. In addition, other recent reports by one of the NonGovernmental Organization, IIZ/DVV [4] found out that the total adult illiteracy rate of women in Ethiopia was $77 \%$ out of the total illiterate population of $64 \%$ of the country. This indicates that three-fourths of women were illiterates in the country.

Furthermore, the annual report of Amhara Regional State Education Bureau in 2013/2014 academic year indicated that about 1,149,453 illiterate women were registered in Functional Adult Literacy Programme based on 
the government's expected plan. However, only 487,933 of them continued learning in the programme throughout the academic year [15]. The above evidences showed that a half and above productive population in the country were neglected from new vocational skills training. So that they are not competitive citizens to challenge the contemporary global issues around in the world.

Although recent researches related to factors affecting women's participation in functional adult literacy are scarce in Ethiopia, a study conducted by Genet and Haftu [16] reveals that perception of women's peers and families has its own implication for women's participation in functional adult literacy at national level.

Nevertheless, this work of study has not emphasized analysis at particular reference to the study area of Bahir Dar Zuria Woreda. Moreover, there was no available previous information on factors affecting women's participation in functional adult literacy in the present study area. Thus, the purpose of this study was identifying factors affecting the selected socio-demographic and organizational factors on the participation of women in Functional Adult Literacy in order to enhance women's participation in Functional Adult Literacy Programme and achieve government development strategy.

\section{Research Methodology}

\subsection{Area of Study}

The study was conducted in Bahir Dar Zuria Woreda which is located in West Gojjam Zone, North West Ethiopia. The woreda has 32 rural kebeles and it is close to Bahir Dar town, which is the capital city of Amhara Regional State. It covers an area of almost $1443.37 \mathrm{sq} \mathrm{km}$. and its administrative office is found in Bahir Dar town. The total population of the study area is 196,766; out of which 100,834 are males and 95,932 are females [17], and almost all of them are farmers. The agriculture dominantly relies upon the seasonal rainfall and uses old traditional method of farming. The farmers make their livelihood by producing food crops and Cash crops, such as fruits and "chat” using small irrigations.

\subsection{Sampling and Research Design}

Quantitative research approach with descriptive survey research design was employed. The targeted population was the registered women from Functional Adult Literacy Centers in 2013/2014 in Bahir Dar Zuria Woreda. A total of 184 respondents were selected through two stage probability sampling procedures. Three kebeles were selected randomly from the 32 rural kebeles in the Woreda. Thereafter, the required sample size was shared among those selected kebeles using probability proportional to size method. Then, the sample population in each kebele selected using simple random sampling with lottery techniques by taking their name from the total number of registered women in each kebele of Literacy Center.

The data examined in the present study came from both primary and secondary sources. For the collection of primary data from the sampled population, structured questionnaire has employed as an instrument. The structured questionnaire covered issues such as socio-demographic and organizational factors. Such variables were selected after reviewing relevant literatures according to the objectives of the study. Secondary data were also sourced from published and unpublished literature to describe the area under study.

\subsection{Data Processing and Analysis}

After collected data from the respondents, survey structured questionnaires initially entered, coded and edited in to Statistical Package for Social Sciences (SPSS) version 20 software. Summary statistics such as frequencies and percentages were computed. Univariate analysis was conducted primarily to check association of each variable with the dependent variable. To control for possible effect of confounding variables found to have association with the dependent variable at p-value 0.05 were entered into multiple logistic regression. Multiple binary logistic regression analysis was also used to identify factors affecting Participation of Women in Functional Adult Literacy where the dependent variable participation is coded (participant as 0 and non-participant as 1). The variables which had sufficient association with p-value was diagnosed after the overall model assessed by Hosmer and Lemeshow goodness of fit tests.

\subsection{Ethical Consideration}

In the data collection methods, negotiation has been made with the respondents to gain permission in order to 
conduct interviews and discussions ethically. Thus, in the present study, a statement of confidentiality, and need and benefits of conducting the study were attached on the cover page of the survey questionnaire. Respondents were informed the purpose of the study. No identity of them was attached to the survey structured questionnaire and the data was handled confidentiality.

\section{Results}

From 184 respondents, 35.3\% of respondents were participant women in Functional Adult Literacy Centers where as $64.7 \%$ of respondents were non-participant women in Functional Adult Literacy Centers after registered in the Centers. Majority, $84.2 \%$ of respondents were ever married while the remaining $2.7 \%, 4.3 \%$ and $8.7 \%$ of respondents were unmarried, divorced and widowed women respectively. The study also shows $31 \%$ of respondents were aged group between 15 and 29, and 69\% of respondents were aged group between 30 and 60 years old. Concerning to their work load status, $84.8 \%$ of respondents who had a high work load while $15.2 \%$ of respondents who had a low work load (Table 1).

As presented in Table 2, on whether inconvenient class room affect or not, $56.5 \%$ of respondents indicated that they were affected by this factor where as $43.5 \%$ of respondents said that they were not affected by inconvenient class room in participating of functional adult literacy. In addition, the study shows $72.3 \%$ of respondents said that they were affected by class schedule conflicts whereas $27.7 \%$ of respondents said that they were not affected by it.

Table 1. Distribution of respondents' responses on socio-demographic features obtained from survey data at Bahir Dar Zuria Woreda, 2014.

\begin{tabular}{cccc}
\hline Variables & Categories & Frequency & Percentage \\
\hline \multirow{2}{*}{ Marital status } & Unmarried & 5 & 2.7 \\
& Married & 155 & 84.2 \\
& Divorced & 8 & 4.3 \\
& Widowed & 16 & 100 \\
Age & Total & 184 & 31 \\
& $15-29$ years old & 57 & 69 \\
& 30 - 60 years old & 127 & 100 \\
Tork load & Total & 184 & 84.8 \\
\hline
\end{tabular}

Table 2. Organizational factors of respondents obtained from survey data at Bahir Dar Zuria Woreda, 2014.

\begin{tabular}{|c|c|c|c|}
\hline Variables & Categories & Frequency & Percentage \\
\hline \multirow{2}{*}{ Does inconvenient of class room affect your participation in FAL? } & Yes & 104 & 56.5 \\
\hline & No & 80 & 43.5 \\
\hline \multirow{2}{*}{ Does class schedule conflict affect your participation in FAL? } & Yes & 133 & 72.3 \\
\hline & No & 51 & 27.7 \\
\hline \multirow{2}{*}{$\begin{array}{l}\text { Does lack of encouragement (e.g. exercise books and pens) from the } \\
\text { government affect your participation in FAL? }\end{array}$} & Yes & 122 & 66.3 \\
\hline & No & 62 & 33.7 \\
\hline \multirow{2}{*}{ Does lack of text books affect your participation in FAL? } & Yes & 117 & 63.6 \\
\hline & No & 67 & 36.4 \\
\hline
\end{tabular}

Note: FAL = Functional Adult Literacy. 
Concerning lack of encouragement from government body, $66.3 \%$ of respondents said that they were affected by this factor where as $33.7 \%$ of respondents said that they were not affected. Moreover, the study findings indicted that $63.6 \%$ of respondents said that they were affected by lack of text books while $36.4 \%$ of respondents said that they were not affected by it (Table 2).

Univariate logistic regression analysis was done to identify factors for multiple logistic regression. In the analysis, marital status, age, work load, class schedule conflict, lack of encouragement from the government body, and inconvenient of class room were selected for the multiple logistic regression analysis based on their p-value of $<0.05$.

The multiple logistic regression revealed that married and divorced women were less likely to be non-participant in functional adult literacy as compared with widowed women keeping other predictors constant. The regression analysis also found that high work load on women increased probability of non participation 3 times than those women who had low work load. Further, the regression showed that those women with class schedule conflict were 8 times likely to be non-participant as compared with women without class schedule conflict (Table 3).

\section{Discussion}

In this study, majority of married women (65.2\%) respondents were non-participant women in Functional Adult Literacy Centers after registered due to their marital status. Previous survey study done in Oyo and Ondo states in Nigeria provides a strong support for the present finding. It is noted that marital status affected married women by $74.3 \%$ in their properly attend in Adult Literacy Centers [18]. Other studies in Kenya [8], and Kabompo District in North Western province in Zambia [9] also showed that married women were strongly influenced by marital status in their participation in Literacy Centers due to lack of support their husbands, and family responsibilities as well as work load at home. Thus, the present study is consistence to the previous studies.

In the study also found out that about $37.5 \%$ of divorced women were non-participant women in Functional Adult Literacy Centers. The result is in line with a study done in Kenya revealed that divorced women regretted to involve in Adult Literacy Centers due to their household headed responsibility and over burden of work load [8].

Moreover, the study revealed that high work load affected to women's participation in Functional Adult Literacy when compare to those women who had low work load. The present study consistent with a study done in Kenya [8], Kabompo District in North Western Province, Zambia [9] indicated that over load tasks in home which contribute to less participation of women in Adult Literacy Centers.

About $72.3 \%$ of respondents were affected by class scheduled conflict. The present analysis in comparison to

Table 3. Multiple logistic regression analysis computed from survey data at Bahir Dar Zuria Woreda, 2014.

\begin{tabular}{|c|c|c|c|c|}
\hline \multirow{3}{*}{ Variables } & \multirow{3}{*}{ Categories } & \multicolumn{2}{|c|}{ Participation of women in FAL } & \multirow{3}{*}{ AOR (95\% CI) } \\
\hline & & Participant & Non-participant & \\
\hline & & Frequency (\%) & Frequency (\%) & \\
\hline Marital status & $\begin{array}{c}\text { Unmarried } \\
\text { Married } \\
\text { Divorced } \\
{\text { Widowed }(\mathrm{RF})^{\mathrm{a}}}^{\text {Widi }}\end{array}$ & $\begin{array}{c}4(80) \\
54(34.8) \\
5(62.5) \\
2(12.5)\end{array}$ & $\begin{array}{c}1(20) \\
101(65.2) \\
3(37.5) \\
14(87.5)\end{array}$ & $\begin{array}{r}0.12(0.007-2.082) \\
0.135(0.024-0.758)^{*} \\
0.054(0.006-0.529)^{*}\end{array}$ \\
\hline Age & $\begin{array}{c}30-60 \\
15-29(\mathrm{RF})^{\mathrm{a}}\end{array}$ & $\begin{array}{l}37(29.1) \\
28(49.1)\end{array}$ & $\begin{array}{l}90(70.9) \\
29(50.9)\end{array}$ & $1.724(0.790-3.764)$ \\
\hline Work load & $\begin{array}{c}\text { High work load } \\
\text { Low work load (RF) }\end{array}$ & $\begin{array}{l}48(30.8) \\
17(60.7)\end{array}$ & $\begin{array}{c}108(69.2) \\
11(39.3)\end{array}$ & $3.326(1.261-8.768)^{*}$ \\
\hline Class schedule conflict & $\begin{array}{c}\text { Yes } \\
\text { No }(R F)^{a}\end{array}$ & $\begin{array}{l}31(23.3) \\
34(66.7)\end{array}$ & $\begin{array}{l}102(76.7) \\
17(33.3)\end{array}$ & $8.009(3.190-20.11)^{*}$ \\
\hline Lack of encouragement & $\begin{array}{c}\text { Yes } \\
\text { No }(R F)^{a}\end{array}$ & $\begin{array}{l}36(29.5) \\
29(46.8)\end{array}$ & $\begin{array}{l}86(70.5) \\
33(53.2)\end{array}$ & $0.794(0.345-1.825)$ \\
\hline Inconvenient of class room & $\begin{array}{c}\text { Yes } \\
\text { No }(R F)^{\mathrm{a}}\end{array}$ & $\begin{array}{l}30(28.8) \\
35(43.8)\end{array}$ & $\begin{array}{l}74(71.2) \\
45(56.2)\end{array}$ & $0.938(0.447-1.967)$ \\
\hline
\end{tabular}

Note: ${ }^{a}$ Reference category, ${ }^{*}$ Significant at 0.05 , p-value of Hosmer and Lemeshow goodness of fit test is 0.720 . 
a study in Kabompo District in North western Province in Zambia was similar in that it also revealed that class schedule problem affected participation of women in adult literacy programme [9].

\section{Conclusion and Recommendation}

In reference to the present findings, it can be concluded that there are different determinant factors that are identified to restrain women's participation in Functional Adult Literacy Programme in Bahir Dar Zuria Woreda. These factors are: marital status (such as married and divorced women), work load and class schedule conflict. So as to solve these factors and enhance the participation of women in Functional Adult Literacy Programme in the study area, the local government body in collaboration with Adult Education Bureau should provide massive awareness creation about gender equality for adult learners and the local communities.

\section{References}

[1] Denial, A.A. and Kofi, A. (2009) The Impact of Functional Adult Literacy on Socio-Economic Lives of Agona District of Ghana. Edo Journal of Counseling, 2.

[2] Oluoch, A., Tmo, A. and Enose, S. (2014) Adult Literacy Programme in Vihiga: The Capacity of Facilitators to Produce Learners with Functional Skills. International Journal of Humanities and Social Science, 4.

[3] UNESCO Institute for Lifelong Learning (2007) Making a Difference: Effective Practices in Literacy in Africa. UNESCO, Hamburg. www.pamoja-west-africa.org/English/Documents/BPEnglish.pdf

[4] Institute for International Cooperation of German/IIZ/DV (2011) Literacy, Skills Training and Entrepreneurship Support for Rural Women in Ethiopia. Bonn, Germany. http://www.dvv-international.de

[5] Corus, C. and Ozanne, L. (2011) Critical Literacy Programes: Can Business Literacy Be a Catalyst for Economic and Social Change? Journal of Macro Marketing, 3, 184-198. http://dx.doi.org/10.1177/0276146710395594

[6] Verner, D. (2005) Policy Research Working Paper 3496, January 2005. http://econ.worldbank.org

[7] UNESCO (2013) Adult and Youth Literacy National, Regional and Global Trends, 1985-2015. UNESCO Institute for Statistics, Canada.

[8] Mualuka, J., Hellen, M., Odeo, I. and Samuel, O. (2009) Adult Education Learners’ Recruitment: Challenges and Prospects for Re-Engineered Access to Adult Education in Kenya. Educational Research and Review, 4, 345-353.

[9] Manda, P.F. (2009) Women’s Participation in Adult Literacy Programme: A Case of Kabompo District in North Western Province. Unpublished Master's Thesis, University of Zambia, Lusaka.

[10] Ministry of Education (2006) National Adult Education Strategy. Addis Ababa.

[11] Ministry of Education (2008) National Adult Education Strategy. Addis Ababa. http://www.mfa.gov.et/docs/Adult\%20Edu.\%20Eng.pdf

[12] Ministry of Education (2005) The Federal Democratic Republic of Ethiopia, Education Sector Development Program III, (ESDP-III) 2005/2006-2010/2011, (1998 EFY-2002 EFY). Program Action Plan. Addis Ababa.

[13] Mammo, K. (2005) Ethiopia: Where and Who Are the World's Illiterates? Background Paper Prepared for the Education for All Global Monitoring Report 2006, Literacy for Life. http://www.ddp-extworldbank.org/Edstates

[14] Central Statistical Authority (2005) Demographic and Health Survey (DHS) Addis Ababa, Ethiopia. http://www.unfpa.org/drive/Gender.pdf

[15] Amhara Regional State Education Bureau (2013) Education Annual Abstract of the Region. Data Collection and Dissemination Supporting Process in the Regional Education Bureau, Bahir Dar.

[16] Gelana, G. and Hindeya, H. (2013) The Impact of Gender Role on Women Involvement in Functional Adult Literacy in Ethiopia: A Review. The International Journal of Social Sciences, 9.

[17] Central Statistical Authority (2011) Central Statistical Authority Abstract of Federal Democratic Republic of Ethiopia. Addis Ababa, Ethiopia.

[18] Abideen, A.O. and Oladiran, I.O. (2013) Adult Learners’ Demographic Variables as Predictor of Access and Participation in Literacy Programmes in Oyo and Ondo States, Nigeria. Academic Journals, 8, 956-966. 